\title{
Unexpected Delayed Rectal Perforation after Endoscopic Submucosal Dissection
}

\author{
Valerii Giorgio $^{1 *}$, Hamanaka Jun ${ }^{1,2,3}$, Costamagna Guido ${ }^{1}$ and Riccioni Maria Elena ${ }^{1}$ \\ ${ }^{1}$ Digestive Endoscopy Unit, Fondazione Policlinico Universitario Agostino Gemelli, Italy \\ ${ }^{2}$ Department of Gastroenterology, Yokohama Minami Kyosai Hospital, Japan \\ ${ }^{3}$ Department of Gastroenterology, Yokohama City University, Japan
}

Submission: October 05, 2018; Published: October 15, 2018

"Corresponding author: Valerii Giorgio,Digestive Endoscopy Unit, Fondazione Policlinico Universitario Agostino GemelliCatholic University, Rome, Italy, Tel:+393804533082; Email: gioval83@hotmail.it

\begin{abstract}
Superficial gastrointestinal neoplasia may be removed endoscopically.ESD (Endoscopic submucosal dissection) isaneffectiveandsafe procedurewhich allows "en bloc" resection of superficial gastrointestinal lesions.The most common adverse events ofESD are perforation and bleeding.Late perforation are rare and occur in $0.22 \%$ according to literature.We report a case of delayedrectal perforation, occurring 16 days after ESDof a 65 x 35-mm laterally spreading tumor (LST) nodular mixed type(G-MIX), ofthe rectum.The perforation wascompletely unexpected because ofabsence of post-ESD risk factors and the long period of wellness of the patient after the procedure.
\end{abstract}

Keywords: Colorectal lesion; Endoscopic Submucosal; Dissection; Delayed rectal perforation

Abbreviations: LST: Laterally Spreading Tumor; G-MIX: Nodular Mixed Type; EMR: Endoscopic Mucosal Resection; ESD: Endoscopic Submucosal Dissection; NBI: Narrow Band Imaging; TEM: Trans analEndoscopic Microsurgery

\section{Introduction}

Superficial gastrointestinal tumor may be removed endoscopically.Endoscopic mucosal resection (EMR) is one ofthe most usefulendoscopic technique toremove gastrointestinal superficial neoplasia,endoscopic submucosal dissection (ESD) is a new endoscopic technique to overcome EMR limits (en bloc resection of lesions larger than $20 \mathrm{~mm}$ or non-lifting lesions).

ESD is nowadays considered an effective and safe endoscopic technique.Colorectal ESD can be consideredto perform en bloc resection of the large lesions ( $>20 \mathrm{~mm}$ ) or to ensure an accurate histopathologic evaluation and a radical treatment with lower risk of relapse[1].

ESD, however,requires greater skill, longer operation time and higher costs than EMRwitha higher incidence of serious adverse eventssuchas immediate (4.2\%) or delayed (0.22\%) perforation[2]. We report a case of laterectal perforation,16daysafterendoscopic removal ofa $65 \times 35-\mathrm{mm}$ laterally spreading tumor (LST) G-MIX(nodular mixed type) in the rectum using a standard ESD technique.

\section{Case Report}

An 82-year-old womanwithout relevant past medical historyexcept for high blood pressure on medication, underwent colonoscopy due to the occurrence of rectal bleeding; colonoscopy revealed a rectalLST G-MIX,starting $15 \mathrm{~cm}$ from the anal canal and extending proximally, measuring $65 \times 35 \mathrm{~mm}$ endoscopically(Figure 1a).Virtualchromoendoscopy (Narrow bandimaging NBI) and after Indigo carmine $(0.4 \%)$ were performed in order to characterize and to establish the feasibility for endoscopic treatment of the lesion(Figure 1b).The lesion had a type IVpit pattern (Figure 1b), according to Kudo classification.ESD was performed underdeep sedation with propofol.Submucosal injection was performed with Glicerol $10 \%$ and sodium chloride $0.9 \%$ mixed with Adrenaline (1:10000) andindigo carmine.

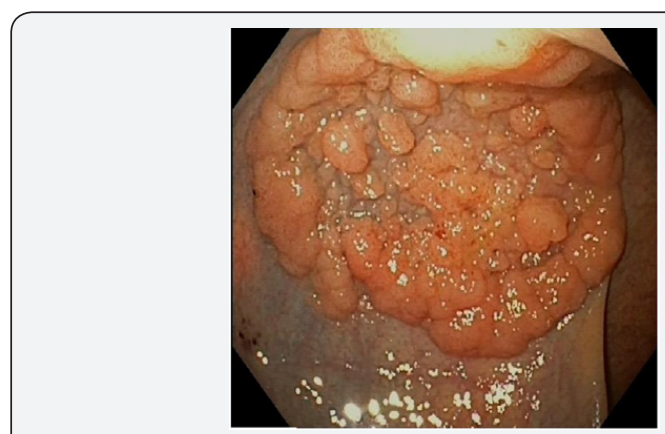

Figure 1(a): Laterally spreading tumor (LST) G-MIX (nodular mixed type) in the rectum. 


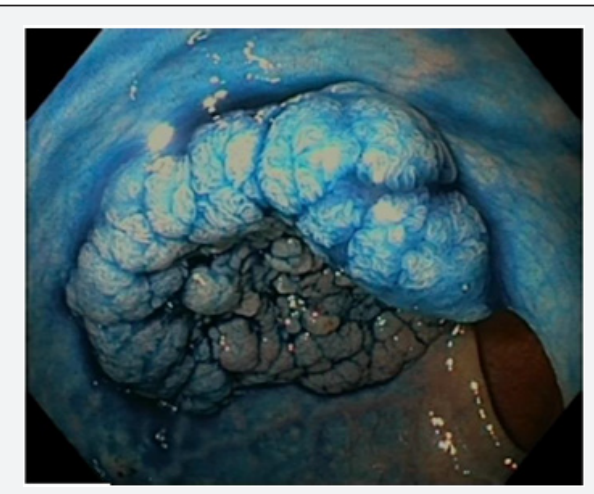

Figure 1(b): Laterally spreading tumor (LST) G-MIX (nodular mixed type) in the rectum after chromoendoscopy with indaco carmine.

Subsequently, circumferential incision to access the submucosa was performedbeginning from the mucosa proximal to the tumor. Local injections were repeated with subsequent dissection of the submucosaover the muscolar layer todistal side of the tumor(Figure 2). Submucosal dissection was performed with the Dual Knife (Olympus, Tokyo, Japan).Coagrasper (FD410LR; Olympus) was performed to coagulate large visible vessels or bleeding sites.Finally, thesubmucosal layer was dissected, and the tumor was resected en bloc (Figure 3).

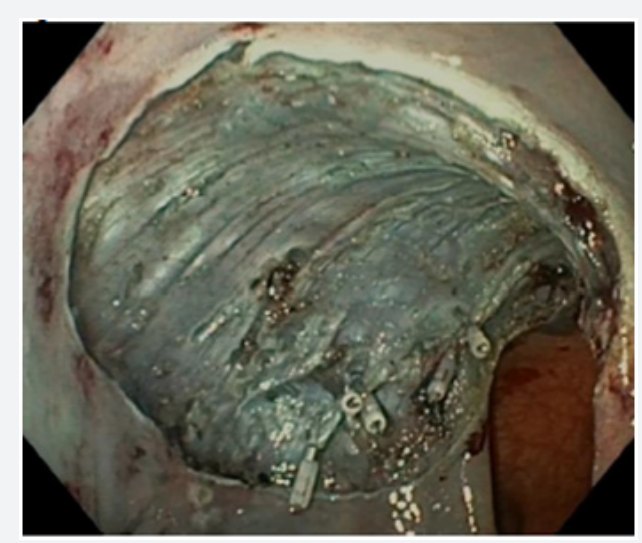

Figure 2: Post-ESD ulcer base with clips, clean without bleeding or severe coagulation injury.

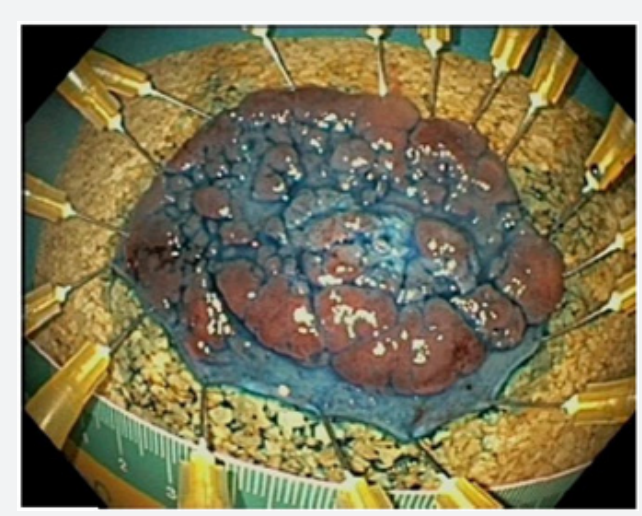

Figure 3: Endoscopic resection specimen with indaco carmine.
The procedure time required for ESD was 70 minutes. Noimmediate procedure-related complications were noted.To prevent late bleeding and perforation, clipping of visible vessel with hemoclip(Olympus, Tokyo, Japan) was4performed.

The tumor measured $65 \times 35 \mathrm{~mm}$ (Figure 3).Microscopic examination revealed a tubulovillous adenoma with high-grade of dysplasia,vertical and lateral margins were negative (Figure 3).There was no evidence of histological damage to themuscolar layerby any cautery effect or air.The following morningher white blood cell count wasnormal.The first follow-up was scheduled, with phone contact, after 10days.

However, 16days after ESD the patient complainedmild abdominal pain andfeverwith a slight leukocytosis. Ultrasonography revealed free fluid with specks of air in peritoneal cavity. CT scan of the abdomen and pelvis revealedintraperitoneal air and fluid inthepelvic region andmesorectum-mesosigmoid with anorganized collection in the presacral space and irregularities at theendoscopic resection site(Figure 4).

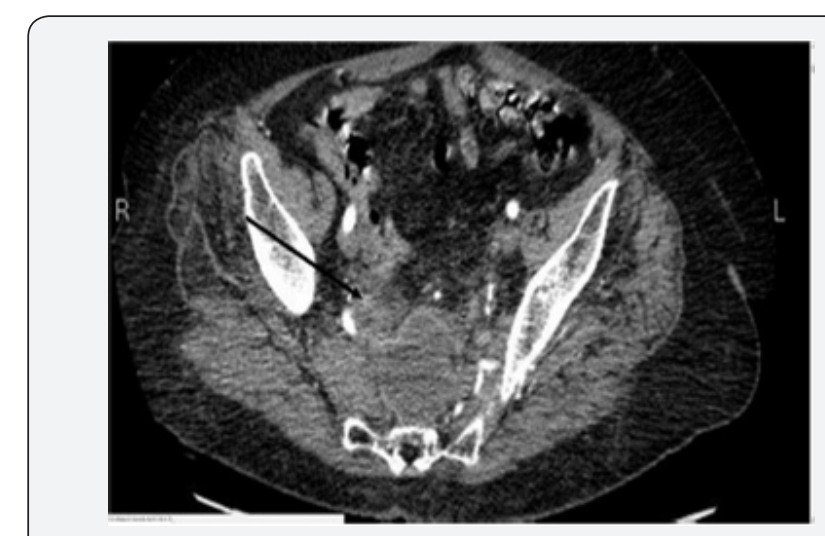

Figure 4: Abdominopelvic computed tomography showing the site of perforation.

Broad spectrumantibiotics were administered,and CT-guided drainage of the pelvic collection was performed.CT-scanwas performed 72hours after the drainage, percutaneous drainage of the collection wasnot effective and due to the persistence of fever and increase of white blood cellthe patient underwent surgery andaloop colostomy of the transverse colon was performed after thorough irrigation of the peritoneal cavity.Post-operative course was uneventful, and the patient was discharged after 7 daysfrom surgery.

\section{Discussion}

Colorectal ESD seems to be an extremely safe andeffective procedure (1) providingen bloc resection with accurate histopathologic assessment particularly for lesions larger than 20 $\mathrm{mm}$,with a relatively low risk of recurrenceand88\% R0 resection rate[3,4].Transanal endoscopic microsurgery (TEM) procedures have ahigherrecurrence ratethan $\operatorname{ESD}(5.2 \%$ versus2.6 \%)[5,6]. The most common adverse events after gastrointestinal ESD are immediate or delayed perforation and major bleeding[1]. 
Risk factors for ESD perforation are well known (fibrosis, lesion diameter(i.e., $\geq 50 \mathrm{~mm}$ ), low endoscopist experiencein ESD) [7].

The reported ratesof immediateand delayed major bleeding, after colorectal ESD, are $0.75 \%$ (95\%CI, 0.31-1.8 \%) and 2.1\% (95\% CI, 1.6-2.6\%); immediate perforation arereported in $4.2 \%$ of the cases (95\% CI, 3.5-5.0 \%)whereasdelayed perforationisvery rare $(0.22 \%, 95 \% \mathrm{CI}, 0.11-0.46 \%)[5]$ and in one-third of the cases diagnosedwithin 24 hours[4].Thirtystudies reported delayed perforation after colorectal ESD in 3887lesions[4].

Abdominal pain, fever and an inflammatory responseare signs and symptoms of supposed delayed perforation, often caused by an electrical or thermal injury after electrocoagulation,also namedCoagulation Syndrome (CS) [8,9].The diagnosis of delayed perforation is performed byCT-scan with contrast[8].CS is an electrocoagulation injury to the muscolaris propria and serosa during polypectomy, EMR orESDthat induces a transmural burn without perforation[7,8,10]. Delayed perforationcaused by CSisusuallysevereand often requiressurgery.3In the current case the rectal perforation was diagnosed16 days after ESD ofan LSTin the rectumand furthermore unexpected.

The patientwas healthy, and the only risk factor washypertension but well controlled with medication;there were no ESD-associated risk factors for perforationexcept tumor size ( $>50 \mathrm{~mm}$ ), no severe coagulation damage was apparent at the postESD ulcer base.Therefore, endoscopists should closely evaluate patient also after clean ESD, and in case of suspiciousabdominal pain perform CT scan with contrast.Delayed perforation,after 16 daysfrom an uneventful procedure,is a rare but possible serious adverse eventof ESD.

\section{Conflict of Interests}

Guido Costamagna has received grant/research support from Olympus Japan, is a member of advisorycommittees or review panels for Cook, Inc., Boston Scientific Corp., and Taewoong
Medical, Inc., and hasbeen a speaker and teacher for Boston Scientific, Corp. and Given Imaging.

\section{References}

1. Pimentel-Nunes P, Dinis-Ribeiro M, Ponchon T, Repici A, Vieth M, et al (2015) Endoscopic submucosal dissection: Endoscopic submucosal dissection: European Society of Gastrointestinal Endoscopy (ESGE) Guideline. Endoscopy 47(9): 829-854.

2. Tamegai Y, Saito Y, Masaki N, Hinohara C, Oshima T, et al. (2007) Endoscopic submucosal dissection: a safe technique for colorectal tumors. Endoscopy 39(5): 418-422.

3. Repici A, Hassan C, De Paula Pessoa D, Pagano N, Arezzo A, et al. (2012) Efficacy and safety of endoscopic submucosal dissection for colorectal neoplasia: a systematic review. Endoscopy 44(2): 137-150.

4. Akintoye E, Kumar N, Aihara H, Nas H, Thompson CC (2016) Colorectal endoscopic submucosal dissection: a systematic review and metaanalysis. Endoscopy International Open 4(10): E1030-E1044.

5. Maslekar S, Beral DL, White TJ, Pillinger SH, Monson JRT (2006) Transanal endoscopic microsurgery: where are we now? Dig Surg 23(1-2): 12-22.

6. Arezzo A, Passera R, Saito Y, Sakamoto T, Kobayashi N, et al. (2014) Systematic review and meta-analysis ofendoscopic submucosal dissection versus transanal endoscopic microsurgery for large noninvasive rectal lesions. Surg Endosc 28(2): 427-438.

7. Kim ES, Cho KB, Park KS, Lee KI, Jang BK, et al. (2011) Factors predictive of perforation during endoscopic submucosal dissection for the treatment of colorectal tumors. Endoscopy 43(7): 573-578.

8. Isomoto H, Nishiyama H, Yamaguchi N, Fukuda E, Ishii H, et al. (2009) Clinicopathological factors associated with clinical outcomes of endoscopic submucosal dissection for colorectal epithelial neoplasms. Endoscopy 41(8): 679-683.

9. Yamashina T, Takeuchi Y, Uedo N, Hamada K, Aoi K, et al. (2016) Features of electrocoagulation syndrome after en-doscopic submucosal dissection for colorectal neoplasm. J Gastroenterol Hepatol 31(3): 615620.

10. Saito Y, Uraoka T, Yamaguchi Y, Hotta K, Sakamoto N, et al. (2010) A prospective, multicenter study of 1111 colo-rectal endoscopic submucosal dissections (with video). Gastrointest Endosc 72(6): 12171225 . 